\title{
Study on the new path of normal university students' modern educational skill cultivation
}

\author{
Feng Liu \\ Linyi university, Linyi Shandong, 276000, China
}

Keywords: Normal college students, Modern educational skill, New path.

\begin{abstract}
China has formulated the great national policy of opening and reform for the purpose of promoting socialist economic development to open the gate to the outside and introduced advanced scientific technology and management experience which has promoted Chinese economic development greatly. In 2001, China has opened the gateway of further opening and reform, joined in WTO solidifying China's status in international stage. The series of measurements have to a large degree promoted Chinese economic development. Chinese government is in urgent demand for high-quality talents and it is urgent to carry out comprehensive quality-oriented education. This article mainly focuses on analyzing and discussing new path contents in modern educational skill cultivation in the teaching process of Chinese normal universities and colleges, and proposes relevant viewpoints for reference.
\end{abstract}

\section{Introduction}

In the advert of 21st century, China started stepping forward to information age in more urgent demand for high-quality comprehensive talents in socialist modernization construction. Education sector as the important institution to delivery talents to social development undertakes crucial historic missions. Normal universities and colleges as important organizations to cultivate education talents for the society, it is key factors for it to own modern teaching skills. Thus related sectors attach great importance to it so that the teaching can better adapt to the current social development and educational demands.

\section{Introduction of modern educational skill and analysis on the necessity of its implementation}

\section{Introduction of modern educational skill}

The so-called modern educational skill mainly refers to a brand new teaching method by using modern teaching model and changing traditional teaching form in the process and integrating computer system and information technology into teaching activity. Compared with traditional teaching method, modern educational skill can help students comprehensively and fast acquire knowledge but also help students improve learning initiative and enthusiasm. Once being launched, it has been widely recognized by all sectors of society and obtained good teaching effect. Besides, as Chinese teaching reform and quality-oriented education is comprehensively launched at present in China, traditional teaching model cannot adapt to the specific demands of Chinese teaching. It is urgent to improve and perfect continuously. Modern teaching skill as the outcome of time development can well cater for the developmental demand of the whole age and play a promoting role for cultivating more high-quality innovative talents. 


\section{Analysis on the necessity of implementing modern educational skill}

This article will make analysis on the necessity of implementing modern educational skill from several aspects as below, detailed contents are as follows:

Modern educational skill can help increase students' learning interest

Higher normal education as the liberal arts education, the teaching content is boring requiring too many memorizing and reciting. Under traditional teaching model, teacher just instruct book knowledge into students who are always in the passive receiving status in the whole teaching activity with limited learning interest. In addition, after being freed from heavy academic pressure of high school, students focus more attention to various after-class activities so that they invest limited energy into study. Thus traditional and single teaching form cannot effectively improve students' learning interest with bad teaching effect. Modern educational skill finds through many years' practical studies that students' each body organs in the learning process will change in a certain degree and each organ's participation into teaching activity will directly influence the teaching effect. Therefore, modern educational skills use multi-media computer and other modern teaching tools in the process of implementation to stimulate students' each organs and create various teaching contexts and to get students participated into teaching activities independently and learn various knowledge in the process of edutainment and further improve teaching efficiency and effect.

Modern educational skill can help promote the cultivation of innovative talents

Traditional teaching model of higher normal specialty is usually single way so that students are always in the passively receiving state in the whole teaching process with low participation and initiative and easy to get bored. Modern educational skill requires for students' full participation in the teaching activity. Teachers can get students participated in the whole teaching activities in the form of assigning after-school work to strengthen the exchange and interaction between students and teachers. Besides, as modern educational skill applies modern electronic computer and internet technology, it can completely break through the time and spatial limitation and get students participated in teaching activities at any time and any location, and to improve their own ability through the communication and exchange between students and teachers to gain win-win.

\section{Analysis on problems existing in current Chinese educational skills}

Through a series of visiting and investigation of the teaching practical condition of normal specialty in some colleges located in the author's city, by combining mass of document and material data, the article summarizes problems existing in the development process of modern educational skills into following aspects, detailed contents are as follows:

\section{Related college leadership pays inadequate attention to modern educational skills}

As traditional exam-oriented education and duck-stuffing teaching model is deeply rooted in China, modern educational skill has been introduced into actual teaching activities, practical teaching activities usually follow traditional model when choosing teaching methods. Teachers instruct education and psychology course and students listen passively so that the teaching effect is limited. The major reason to cause the current situation is that the college leaders do not recognize and pay attention to modern educational skills. Firstly, in practical teaching activities, there is no systematic and clear teaching objective and college leaders and teachers do not know the real meaning of teaching. Secondly, through a series of investigation and survey and studies on related material data, we also find that teachers working in higher normal college teaching are in old age who are cultivated by traditional educational model, thus they do not know modern educational skill itself, let alone integrating it into daily teaching activities scientifically and effectively. They lack the attention to modern educational skills. Thirdly, at present stage, modern education technological level in Chinese high normal college is low and many teachers do not know modern educational skill, let alone teaching. Bedsides, due to the existence of backward teaching management system, it is difficult to apply modern educational technology in college education. 


\section{Lack of modern education teaching facilities}

As Chinse socialist modernization progress is being promoted at present stage, China's comprehensive power and international competition has been developed significantly, especially in recent years as China has strengthened opening, Chinese' comprehensive power has been improve greatly. Our party and related educational sectors have invested huge manpower, material and finance into educational industry for further promoting educational development and obtained significant progress. But as the time of China to introduce modern educational technology is limited, the equipment introduction is limited. With the further expansion of college recruitment, the continuous increase of teaching staffs have made each student have less educational facilities and many colleges cannot effectively satisfy each student's demand of using modern educational skill. Besides, many teachers still get used to using traditional teaching methods an facilities in daily teaching activities and seldom use modern educational technologies so that the overall teaching effect is not good enough.

\section{Lack of scientific and reasonable curriculum setting system}

Through a series of visiting and investigation of the teaching practical condition of normal specialty in some colleges, this article finds that many colleges has set up the course in daily teaching activities to respond the educational sectors' appealing of modern educational skill course. But in practical teaching activities, it is necessary to set up suitable computer application basic courses to effusively improve the teaching effect. But many colleges never implement for saving teaching time and cost. In addition two course belong to different departments, so there exist many teaching barriers in teaching activities. Especially in recent years, most colleges and universities' objective in computer teaching activity is computer grade examination so that there still exist some barriers in practical learning skill cultivation and the overall teaching effect is not good. This kind of situation is urgent to be improved.

\section{Studies on the new path of cultivating normal university students' modern educational skills}

This article will illustrate the new path of cultivating normal university students' modern educational skills from below aspects, detailed contents as below:

\section{Establish modern language lab}

To improve normal university students' modern educational skills, related college leadership can consider establishing language labs in teaching activities and improve their learning interest and initiative to participate in learning activities through fully integrating with modern educational technologies. Specifically, the detailed procedures of language lab teaching are as below: firstly, teachers can choose courses suitable courses for language lab based on practical teaching demands for simulation teaching and record students' lecture contents. Secondly, teachers play the records to students repeatedly for their self-evaluation and correction through the contents of record. Thirdly, get students into the language lab for second simulation teaching and record. Fourthly, teachers make explanations on students' various performance of students when listening to the second simulation records so as to help them precisely know their disadvantages and defects and improve and perfect themselves in future learning activities.

\section{Apply modern multi-media and network interactive learning model}

As the increasing economic and globalization tendency, our party and related governmental sectors have introduced mass of modern scientific technologies to further promote Chinese modernization construction and development, during the process, the technology level of all walks of China have been improved significantly. Thus, to effectively improve the teaching effect and level of modern educational skill in college normal specialty, related school leadership can consider introducing and applying more modernized multi-media and network interactive learning model and fully make use of network resources to improve students' learning interest, and create more teaching contexts for students to attract them to participate into teaching activities independently, and improve their 
cooperation ability in the exchange and interaction context model, and further promote better teaching effect.

\section{Establish and perfect scientific curriculum setting system}

There exist huge problems in the setting of modern educational skill in course setting in traditional college normal specialty, without the support from other courses for modern educational skills. So to improve the current situation, school leaders should find the core and breakthrough of course teaching when setting up courses to design professional curriculum system, and equip modern teaching facilities and tools based on the curriculum setting to provide good teaching practice based for students Some colleges with better conditions can set up professional teaching software to help students fully participate into teaching activities and boldly express their viewpoints, strengthen the communication with teachers and classmates and promote better teaching effect.

\section{Provide regular training for teachers}

After investigating the practical condition of teachers in Chinese college normal specialty at present stage, we find that the old age structure and learning awareness deviation are main issues existing in current teaching. Teacher as the important participant in teaching activities, their qualities will produce important impact on teaching activities. Thus related colleges should arrange teachers for regular training, especially training on modern educational skills, and truly put into practice, completely change the traditional and single teaching model and step forward to brand new teaching model.

\section{Conclusion}

Through a series of analysis and discussion on the new path of applying modern educational skills in Chinese normal college professional teaching, the article proposed related viewpoints, for the purpose of promoting the teaching work in future college normal specialty and further promoting the development of Chinese college teaching and cultivating more excellent talents for Chinese socialist modernization construction and development.

\section{Reference}

[1] Huang Yuhua, Li Zhifang. Discussion on the cultivation of normal college students' teaching skill in Chinse college physical education specialty- thinking through analyzing the national physical education specialty basic skill competition, Journal of Huizhou University, 2016(03).

[2] Xiong Mng. New path of normal college students' modern educational skill cultivation, Journal of Hubei University of Economics (humanistic and social science version), 2016(04).

[3] Peng Yingjuan. Studies on normal college students' teaching ability cultivation model based on quantitative method, Yunnan Normal University, 2015.

[4] Zhou Pei. Studies on the reform strategies of public course teaching in "modern educational technology" for students of higher vocational teachers college under competency-based perspective, Zhejiang Normal University, 2013.

[5] Zhang Yuexi, Liu Lina. Construction of the multi-purpose training system of normal college students' modern educational technology ability, Contemporary Education Forum (comprehensive research), 2011(05).

[6] Chen Jun. Studies on the educational skill cultivation of English majors in local normal colleges, Journal of Yangtze University (Social Science Edition), 2011(05).

[7] Meiduo Zhuoma. Exploration of skill cultivation for students major in ideological and political education specialty in Tibetan colleges,Tibetan Education, 2014(08). 
[8] Liu Yan. Studies on micro-video resource platform development targeting at normal college students' teaching skill cultivation, Zhejiang Normal University, 2014. 